\title{
CRIME RECONSTRUCTION, A TOOL TO SOLVE MYSTERY AND ACHIEVE JUSTICE - AN INTERESTING CRIME SCENE REPORT
}

\author{
T. Nataraja Moorthy* \\ *Corresponding author and Professor of Forensic Sciences, Department of Diagnostic and \\ Allied Health Science, Faculty of Health and Life Sciences, Management and Science \\ University, Shah Alam, Selangor, Malaysia. \\ Formerly Government Forensic Crime Scene Investigator (India) \\ Email: natrajamoorthy@ rediffmail.com, Hand phone: +6 0129224610
}

Received: 13 August 2020

Revised: 20 September 2020

Accepted: 28 September 2020

Published online: 1 December 2020

\begin{abstract}
Crime reconstruction or crime scene reconstruction is the forensic science discipline in which one gains "explicit knowledge of the series of events that surround the commission of a crime using deductive and inductive reasoning, physical evidence, scientific methods, and their interrelationships". A competent crime scene Reconstructionist must understand the value of various piece of evidence and need to fit within the overall context of the scene. The dead body is the most valuable piece of potential evidence at any death scene. Both forensic crime scene and autopsy officers should undertake a systematic and keen examination of the deceased. There are instances wherein dilemmas arise regarding the manner and cause of death among officers in particular, crime scenes of suspicious death cases. The following is a case report in a suspicious death scene wherein a boy aged about 18 years found dead under a tamarind tree. His body found decomposed with a rope around the neck. The cause and manner of this suspicious death, an alleged homicide case was solved as suicidal death through crime reconstruction based on physical evidence and the justice was achieved. The fact was explained to family members of the deceased in the crime scene itself and they accepted the forensic explanation.
\end{abstract}

Keywords: Forensic Science; Crime scene; Suspicious death; Crime reconstruction

\section{INTRODUCTION}

The term Forensic (forensis, in Latin) means a public platform for discussion or debate. However, in modern context, forensic means answering the court for any dispute in legal system. Crime means any illegal or unlawful act of an individual or group and physical evidence identifies the actor/perpetrator forensically. The actors unconsciously left their body physical evidences at the crime scenes, which lead to award sentences by Judicial Authority (Fisher and Fisher, 2012).

Hence, a keen crime scene observation and examination is an important component to an investigator (Moorthy and Khaja, 2019A). In many incidences, the court required the crime reconstruction to understand the activity and behaviour of actors or perpetrators. Researchers have indicated that some of the investigating officers intentionally neglected some 
physical evidences such as hair, fibre, footprint, soil etc. considering unimportant (Moorthy, 2017; Moorthy 2019B). Every crime scene is different from others and no two-crime scenes are identical.

Investigation on homicide, suspicious death, and accidental death is challenging to the crime scene investigator, particularly when dealing with decomposed dead bodies or dismembered body parts found at the crime scenes. External examination of the dead body in the crime scenes by the forensic crime scene investigator and internal examination of the body in the autopsy room by forensic autopsy expert have an impact on judicial decisions. Examination of dead body in the crime scenes provides information about the primary crime scene, when falsely created by the perpetrator in hit and run death cases and so on (Moorthy, 2019C ; Moorthy, 2020). Crime reconstruction or crime scene reconstruction is the forensic science discipline in which one gains "explicit knowledge of the series of events that surround the commission of a crime using deductive and inductive reasoning, physical evidence, scientific methods, and their interrelationships (Gardner and Bevel, 2009).

\section{METHODOLOGY}

Case history: An unidentified decomposed male dead body aged about 18 years found dead under a tamarind tree. The body found on one side of the tree and bloodstain on the other side. The body found in the crime scene was as shown in figure (1). Police registered a case under "suspicious death" section and initiated the investigation process. The inspector of police requisitioned the service of forensic crime scene investigator to visit the death scene and assist the investigation.

Description: The crime scene officer visited and documented with sketch and photography. The male body was identified as a local village boy aged about 18 years. The father was working at Singapore and not in the village. The mother of the deceased and the villagers have alleged homicide on seeing the dead body. The crime scene investigator examined the dead body that found under the tamarind tree and observed a creeper plant cord tied around the neck that made to presume the case as homicide. On the floor under the tree, the body found on the western side of the tree trunk while bloodstains on the eastern side. The author have climbed on the tree, examined the inner branches of the tree, and found a rope-like creeper plant, one end tied on a stem branch and other irregular end found hanging on the eastern side of the tree. Just below the hanging creeper plant, noticed a V shaped branch stained with bloodstain on one side of V shaped.

Autopsy: The decomposed body then sent to Department of Forensic Medicine for autopsy. As informed by Superintendent of Police (SP) and Professor of Forensic Medicine (PFM), the author had attended the autopsy room to observe the internal examination of the body during autopsy. The forensic medicine team have conducted the autopsy and the hyoid bone found broken. 

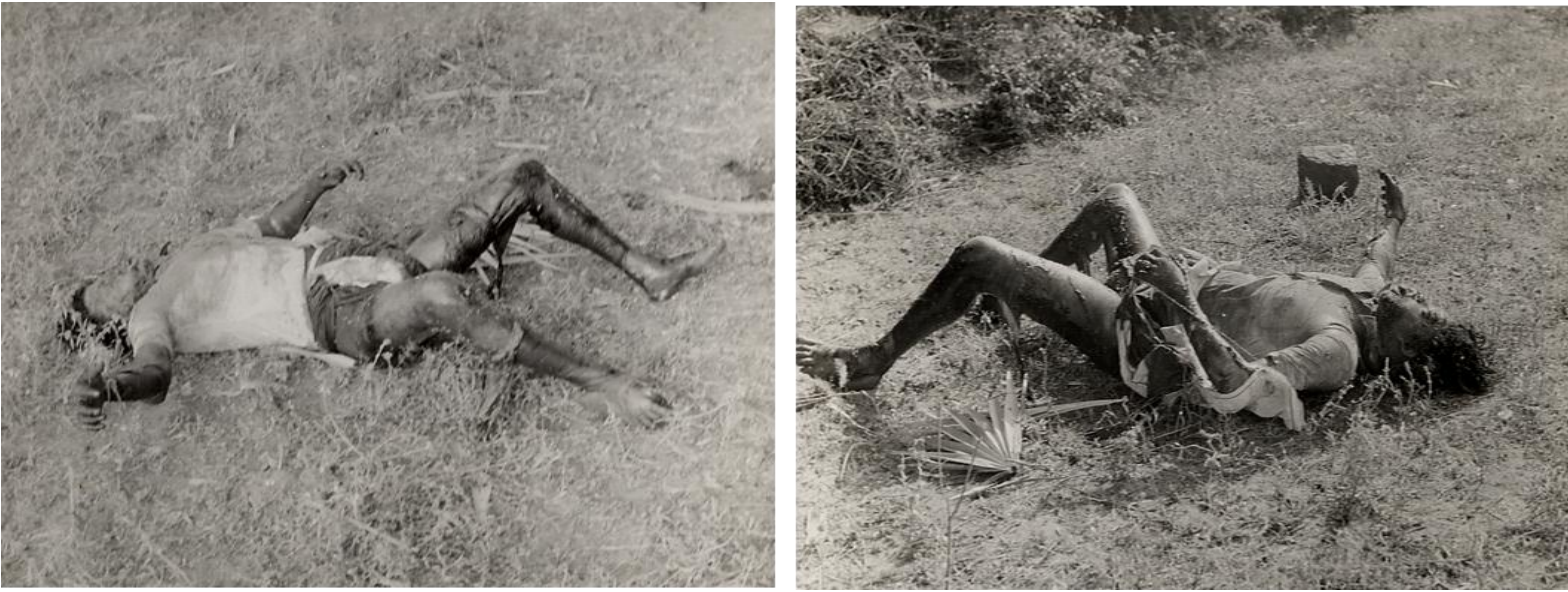

Figure 1: Different poses of decomposed male dead body in the crime scene

\section{RESULTS}

\section{Reconstruction:}

On detailed examination of the crime reconstructed the crime scene as shown in scene and deceased, the author had figure (2).

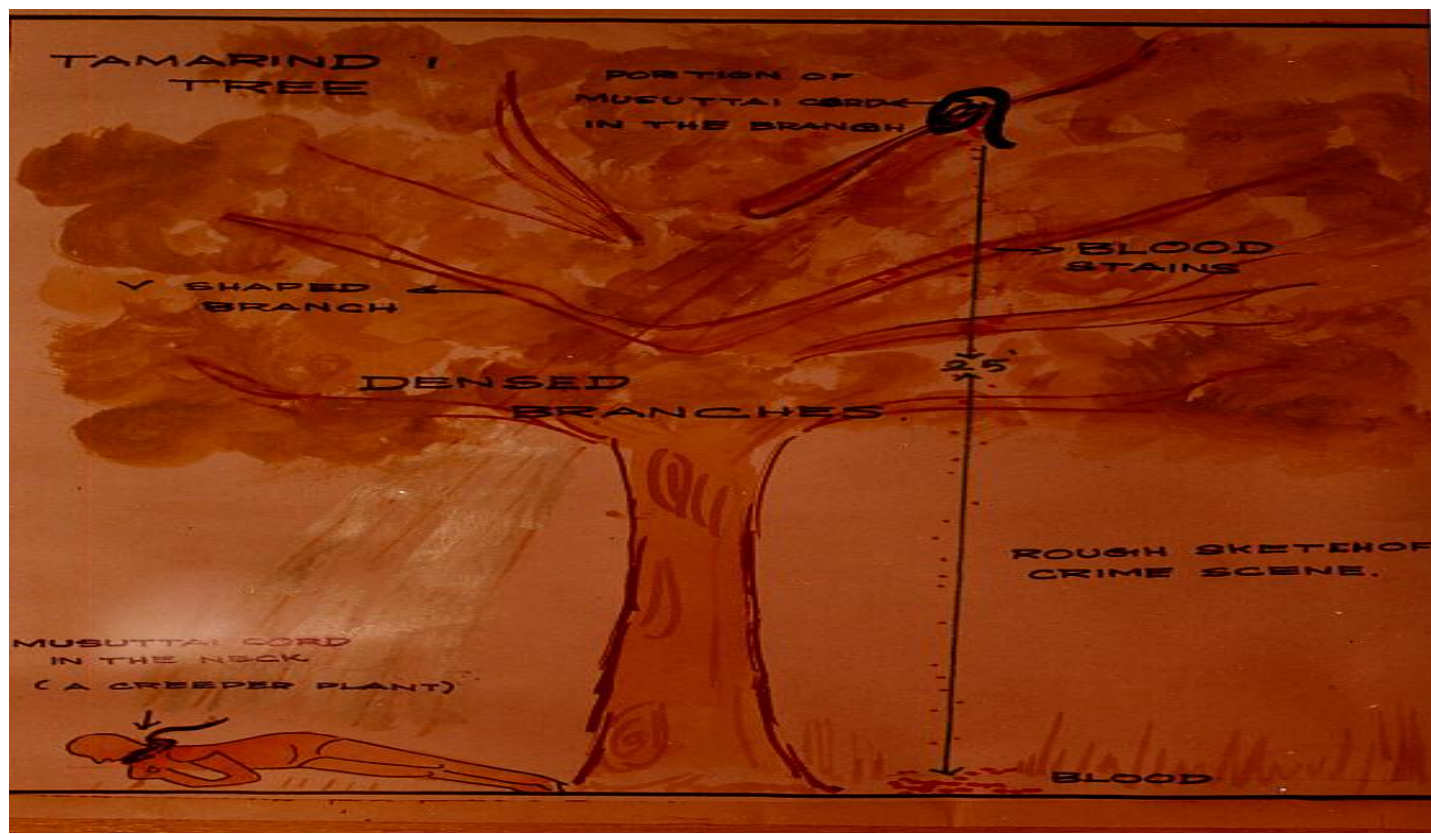

Figure 2: Crime scene sketch showing the overall crime scene for reconstructio

The tree found in the outskirt of the village with rare people mobility. The examination of the hanging rope showed that it is a creeper plant found in that area 
and the people used this creeper plants to tie the firewood sticks and for other bundling process. I have examined the broken end of hanging rope and free end of rope on the neck of dead body, conducted physical matching of the ends, and found satisfactorily matched. Using this creeper plant, the boy should have committed suicide by hanging in a tamarind tree in the eastern side branch.

\section{DISCUSSION}

When the dead body was hanging on multiple days, it decomposed and changes occurred on the dead body because of complex physicochemical and environmental process and the skin was pale ashen. Any changes in the position of the body causes blood to settle down in the newer dependent areas, referred to as 'shifting of post-mortem lividity' (Mann et al, 1990). Accordingly, while the dead body was in hanging position for many hours, discharging of blood from nose, mouth and other holes possibly dropped to the ground by gravitation force, as found on the eastern side ground of the tree. As the body was in hanging for long time, at one stage, the plant cord was unable to bear the decomposed weight of the dead body and broken in the middle of hanging plant cord and the hanging body might have fallen towards the floor. On the way to fall, the body might have fallen on the $\mathrm{V}$ shaped branch and hence the direction of fall changed to the opposite side, and dropped on the other side of hanging point, i.e. western side of the tree where the body was found in the crime scene. The presence of bloodstains on the eastern side of the floor and branch below the plant rope is the clear evidence showing the position of the hanging body and dropping of blood while hanging. In addition, there may be possibility of hyoid bone fracture while hanging since the rough outer cuticle of creeper plant may provide pressure on the neck that led to hyoid bone fracture. Researchers have shown that hyoid bone fracture is possible in suicidal hanging cases also (Green et al., 2000; Nantana et al., 2010). PFM discussed with the author regarding his crime scene findings and suggested the possibility of hyoid bone fracture caused by the creeper plant constriction based on crime scene findings and other internal observations. The crime reconstruction and autopsy findings found coincided.

Based on crime scene evidence and reconstruction, finally the cause of death reported as suicidal hanging and not homicidal hanging. Police enquires revealed that since the father was working in Singapore, the boy was acting on his own way with irregular school attendance, disobedient to his mother, teacher and seldom stay at home. Because of this misbehaviour, sometimes the mother angrily used to scold him as, "instead of troubling, better go and die" and these harsh words might have hurt his mind that led to the decision of committing suicide. Both crime scene report and autopsy report submitted to the police officer as acknowledged and the puzzle of suspicious death was solved. The crime scene officer explained the reconstruction of the crime scene to the family members of the deceased in the crime scene itself. Therefore, the family members too have accepted the fact based on forensic evidence as explained by the forensic crime scene officer. Researchers have shown that family members of the victims have accepted the forensic findings in the crime scenes whenever explained by the forensic crime scene investigators. (Moorthy and Murty, 2019D). Thus, the crime reconstruction based on physical evidence solved the mystery in a puzzle of death and established justice.

\section{CONCLUSION}

Modern medico legal death investigation has evolved into a discipline of forensic science using both forensic medical practitioners and forensic crime scene investigators. The crime 
reconstruction is a mandatory step for maintaining the integrity of a crime scene. The case study report presented here based on ability to make keen observation at the scene, the scientific ability to examine physical evidence, and the use of logical approaches to theory formulations.

\section{ACKNOWLEDGEMENT}

The author is thankful to Management and Science University for the encouragement in research and publications.

\section{REFERENCES}

Fisher, AJ and Fisher, DR. (2012):

Techniques of crime scene investigation. Boca Raton, Florida: CRC Press.

Gardner, R and Bevel, T. (2009):

Practical crime scene analysis and reconstruction. Boca Raton, Florida: CRC Press.

Green H, James RA, Gilbert JD and

Byard RW. (2000): Fractures of the hyoid bone and laryngeal cartilages in suicidal hanging. J Clin Forensic Med. 7(3): 123-126.

DOI: $10.1054 / j c f m .2000 .0419$

\section{Mann RW, Bass WM and Meadows L.}

(1990): Time scene death and decomposition of the human body: variables and observations in case and experimental field studies. J Forensic Sci. 35(1): 103-111.

DOI:10.1520/JFS12806J

Moorthy TN. (2017): Neglected
Physical Evidence during crime scene investigation. Forensic Sci Addi Res. $1(2): 1-2$.

Moorthy TN and Khaja M. (2019A):

Robber's handwritings on the wall solved the mystery: A rare crime scene report. J South India Med-legal Assoc. 11(2): 119-123.

Moorthy TN. (2019B): Footprint evidence solved the mystery in a suspicious death: A rare case report. Peer Rev J Forensic Gene Sci. 3 (2):183-185. DOI:10.32474/PRJFGS.2019.03.0001 56.

Moorthy TN. (2019C): Hit and Run

Road Accident: Handwriting characteristic identified the offending vehicle. JJ Forensic Sci. 4(1):1-4.

Moorthy TN and Murty OP. (2019D):

Suspicious death - Crime scene evidence indicated the cause of death: An interesting multiple death case report. Int J Med Tox Leg Med. 22 (12): $5-7$.

DOI: 10.5958/0974-4614.2019. 00002.0

Moorthy TN, Santhra Segaran B and Srinivasan M. (2020): Suspicious

death - Trace evidence identified the complaint as accused: A real crime scene report. Int $\mathbf{J}$ Med Tox Leg Med. 23 (1-2): 117-119.

DOI: $10.5958 / 0974-4614.2020 .00018 .2$

Nantana C, Paitoon N and Somsak V.

(2010): Fractures of the hyoid bone and thyroid cartilage in suicidal hanging. $\mathrm{J}$ Med Assoc Thailand. 93(10): 1211-16. 